Article

\title{
Residual Stress-Strain Relationship of Scoria Aggregate Concrete with the Addition of PP Fiber after Fire Exposure
}

\author{
Bin Cai ${ }^{1}$, Yu Tao ${ }^{1}$ and Feng Fu ${ }^{2, *(D)}$ \\ 1 School of Civil Engineering, Jilin Jianzhu University, Changchun 130118, China; caibin@jlju.edu.cn (B.C.); \\ 15842033023@163.com (Y.T.) \\ 2 School of Mathematics, Computer Science and Engineering, City, University of London, \\ London EC1V 0HB, UK \\ * Correspondence: feng.fu.1@city.ac.uk
}

Citation: Cai, B.; Tao, Y.; Fu, F. Residual Stress-Strain Relationship of Scoria Aggregate Concrete with the Addition of PP Fiber after Fire

Exposure. Fire 2021, 4, 91.

https:/ / doi.org/10.3390/ fire4040091

Academic Editor: Maged A. Youssef

Received: 9 November 2021

Accepted: 2 December 2021

Published: 5 December 2021

Publisher's Note: MDPI stays neutral with regard to jurisdictional claims in published maps and institutional affiliations.

Copyright: (c) 2021 by the authors. Licensee MDPI, Basel, Switzerland. This article is an open access article distributed under the terms and conditions of the Creative Commons Attribution (CC BY) license (https:// creativecommons.org/licenses/by/ $4.0 /)$.

\begin{abstract}
Scoria aggregate concrete (SAC) as new green material has been gradually used in some construction projects for its lightweight and high strength, which can reduce the environmental impact of construction materials. In this paper, the residual mechanical properties and intact compressive stress-strain relationships of polypropylene (PP) fiber-reinforced Scoria aggregate concrete after high-temperature exposure at $20,200,400,600$, and $800{ }^{\circ} \mathrm{C}$ were investigated. The failure modes of PP fiber-reinforced Scoria aggregate concrete specimens and the effect of high temperatures on the peak stress, secant modulus, and peak strain were obtained. The results showed that the residual compressive strength of heated concrete is significantly reduced when the temperature exceeds $400{ }^{\circ} \mathrm{C}$. The residual strength and residual secant modulus of PP fiber-reinforced Scoria aggregate concrete are significantly higher than those of ordinary concrete. The Scoria aggregate concrete specimens with PP fibers exhibited fewer surface cracks and fewer edge bursts under high temperatures. The residual stress-strain equation of the Scoria aggregate concrete was established by regression analysis, which agreed well with the experimental results.
\end{abstract}

Keywords: Scoria aggregate concrete; PP fiber; high temperature; stress-strain curve

\section{Introduction}

With the development of modern building structures with large spans, high rises, and super high rises, concrete that is lightweight, high-strength, and sustainable is needed to lower the structural weight and improve the thermal insulation. Lightweight aggregate concrete has a high quality, is widely used [1], and has long-term performance in buildings [2]. Although it is possible to meet structural strength requirements by using artificial aggregates to make lightweight aggregate concrete, the consumption of materials and energy is often substantial. Therefore, it is important to find natural aggregates with good material properties. Scoria aggregate, which is abundant in Northeast China [3] and is very clean, is one such material. Scoria aggregate concrete is characterized by its high strength, heat insulation, light weight, fire resistance, good deformation performance and low modulus of elasticity [4], and these characteristics can reduce environmental impacts when this material is used in buildings.

Scoria aggregate concrete has excellent compatibility, strength, and water permeability characteristics [5] and good chemical resistance, which enables it to maintain a stable state under acidic conditions with less mass loss [6]. Blocks made from Scoria aggregate concrete are $30-40 \%$ lighter in weight than normal concrete with the same strength [7]. As a result, it has wide application prospects [8]. In recent years, the use of this material has increased owing to the increasing demand for environmentally friendly materials and green buildings, and research on it has further developed. Willy H. Juimo Tchamdjou et al. [9] prepared two sets of natural light-aggregate concrete specimens and investigated the performance of Cameroonian Scoria aggregate concrete compared to ordinary lightweight concrete. The 
tests showed that the compressive strength of this concrete increased by $27.42-35.36 \%$, proving that Cameroonian Scoria aggregate concrete can be used as structural concrete. Ahmed A. Abouhussien et al. [10] conducted an experimental study on lightweight slag aggregate concrete and showed that concrete beams mixed with lightweight slag aggregates exhibited higher shear strength compared to normal concrete beams. Kozo Onoue et al. [11] investigated the shock absorption capacity of volcanic pumice lightweight concrete through experiments. The results showed that lightweight concrete had a better damping capacity than the control concrete, which used limestone powder as the coarse aggregate, and was on average 28 and $41 \%$ more efficient than the two control concretes in decreasing the maximum impact loads at impact velocities of 1.5 and $4.5 \mathrm{~m} / \mathrm{s}$, respectively. J. Alexandre Bogas [12] studied the application of nonstructural lightweight concrete produced using Scoria aggregate in building floor slabs and investigated its mechanical properties. Scoria aggregate concrete containing slag exhibited a similar mechanical strength and better hightemperature properties compared to normal concrete. Aref M. al-Swaidani [13] analyzed the effect of parameters such as the cement content, the Scoria aggregate content, and the water content on other properties by building a neural network model.

Accidental fires are a major cause of durability problems in concrete structures. Aggregate replacement and fiber addition are feasible methods to improve the fire resistance of concrete structures. Generally, concrete structures perform well in fires, but concrete without significant damage may also show a decrease in strength because of an increase in temperature [14]. Therefore, it is important to investigate the reduction in the mechanical properties of concrete after the fire to evaluate and repair fire-damaged concrete elements. At present, the main studies include the basic mechanical properties of lightweight aggregate concrete after exposure to high temperatures and the full stress-strain curve of light-aggregate concrete [15]. Chang, Y. F. et al. [16] conducted an experimental study on the complete stress-strain relationship of concrete after high temperature. The temperature effect on the mechanical properties of the material and the full curve model of stress-strain were obtained by regression analysis. Krzysztof Drozdzol [17] studied the feasibility of using perlite concrete blocks for chimneys. The tests proved that although the thermal loading reduced the compressive strength of the chimney blocks, they still showed an adequate average strength of 4.03 MPa. Shoroog Alraddad [18] analyzed volcanic rocks by temperature difference analysis and thermogravimetric analysis and found that volcanic rocks have good thermal stability and are a highly available and low-cost natural material. Khandaker M. Anwar Hossain [19] studied high-strength Scoria aggregate concrete at $800^{\circ} \mathrm{C}$ for strength and durability, and compared with a high-strength concrete control, this material showed a better performance in terms of the residual strength, resistance to chloride ion attack, and resistance to high-temperature deterioration. Waqas Latif Baloch [20] studied the effect of incorporation of multi-walled carbon nanotubes on concrete. The results showed that the incorporation of multi-walled carbon nanotubes could improve the strength of concrete both prior to and after exposure to fire. C. Maraveas [21,22] conducted a sensitivity study on the performance of 19th century fireproof flooring systems at high temperatures, and the applicability of the Eurocode expressions to 19th century fireproof flooring systems is satisfactory. Incorporating appropriate amounts of polypropylene (PP) fibers into concrete not only improves the material properties but also enhances its fire resistance and prevents high-temperature bursting [23]. Nicolas Ali Libre et al. [24] tested experimentally the effectiveness of nine mixtures of steel and polypropylene fibers with different volume fractions to improve the ductility of lightweight pumice aggregate concrete. Studies have shown that steel fibers show a very significant improvement in flexural properties, while the improvement in compressive strength is smaller. PP fiber incorporation has little effect on the mechanical properties of concrete. Xi Liu et al. [25] conducted 30 group experiments to investigate whether the incorporation of fibers could positively affect the mechanical properties and axial stress-strain behavior of lightweight confined carbon fiber aggregate concrete. The peak stresses and corresponding strains were modeled and were in good agreement with the experimental results. According to 
the test results, the optimum dosing of both steel fiber and carbon fiber is $0.6 \%$. Vahid Afroughsabet [26] investigated the effect of incorporation of steel and polypropylene fiber mixture with $1 \%$ volume dose on the mechanical properties and some durability of highstrength concrete. The results showed that the incorporation of $1 \%$ volume dose of steel and polypropylene fiber mixture significantly improved the mechanical properties of highstrength concrete. Li Jing Jun et al. [27] analyzed the influence of high-performance PP fibers on the mechanical properties of light-aggregate concrete. It was found that the incorporation of high-performance PP fibers significantly improved their mechanical properties, with an increase in the bending strength, splitting tensile strength, bending toughness, and impact resistance but no significant influence on the compressive strength. To achieve more accurate experimental values in prismatic uniaxial compressive experiments, Liu [28] used the digital image correlation (DIC) method to measure the displacement and strain values of the specimens to obtain their strain clouds, which can reveal phenomena such as regions of crack occurrence and stress concentration. Scoria aggregate concrete has been widely studied because of its many advantages, but the mechanical properties of PP fiber-reinforced Scoria aggregate concrete after exposure to high temperatures and its stress-strain relationship have not been reported.

The purpose of this paper is to obtain the mechanical property and residual stressstrain relationship of Scoria aggregate concrete after high temperature. The data obtained are very important for the design and analysis of building structures, but there are few studies on the stress-strain constitutive relationship of Scoria aggregate concrete after fire exposure. Therefore, we conducted some mechanical tests to obtain the compressive strength and splitting tensile strength of Scoria aggregate concrete after high temperature and measured the residual compressive stress-strain relationship after high-temperature exposure by an advanced DIC system to obtain the changes in peak strain, secant modulus, ultimate strain, and deformation capacity of Scoria aggregate concrete at different temperature exposure levels. In addition, the regression analysis of the experimental results led to the establishment of the constitutive relation equation of Scoria aggregate concrete after high temperature, which provides a reference for the fire design of PP fiber-reinforced Scoria aggregate concrete structures and the evaluation and repair after fire.

\section{Experimental Program}

\subsection{Materials and Mix Proportion}

The high-strength Scoria aggregate concrete used in this study was designed according to the JGJ51-2002 Technical Specification for Lightweight Aggregate Concrete to produce a design strength grade of C30 and an average density of $1900 \mathrm{~kg} / \mathrm{m}^{3}$. The mixture proportions are shown in Table 1. Scoria aggregate concrete is made of volcanic slag aggregate, normal Portland cement, styrene-acrylic emulsion, grade II fly ash, PP fibers, and water. The raw material is shown in Figure 1. The porous Scoria aggregate with a bulk density of $815 \mathrm{~kg} / \mathrm{m}^{3}$ was produced in Gushanzi, Huinan County, and artificially pulverized into a continuous gradation of $5 \sim 40 \mathrm{~mm}$. The stone for normal concrete is ordinary gravel with a grading size of $5-25 \mathrm{~mm}$, and the sand is ordinary river sand with a fineness modulus of 2.8. P O 42.5 ordinary silicate concrete was used in the mix, initial setting time: $85 \mathrm{~min}$, final setting time: $260 \mathrm{~min}$, compressive strength: $43 \mathrm{MPa}$ (28 days). The bundled monofilament PP fibers had a length of $9 \mathrm{~mm}, 400 \mathrm{MPa}$ tensile strength, $160{ }^{\circ} \mathrm{C}$ melting point, and a PP fiber content of $0.22 \%$ by volume. Tap water was used for mixing.

Table 1. Mix proportion $\left(\mathrm{kg} / \mathrm{m}^{3}\right)$.

\begin{tabular}{ccccccccccc}
\hline Type & W/B & SA & Gravel & Sand & Cement & Fly Ash & SAE & WRA & PP Fiber & Water \\
\hline NC & 0.5 & - & 1192 & 596 & 370 & 54 & 5.4 & 0.47 & - & 185 \\
SAC & 0.46 & 1110 & - & - & 496 & 54 & 5.4 & 0.47 & 2 & 230 \\
\hline
\end{tabular}

$\mathrm{W} / \mathrm{B}=$ Water $/$ Binder ratio; SA = Scoria aggregate; SAE = Styrene-acrylic emulsion; WRA = Water-reducing admixture. 


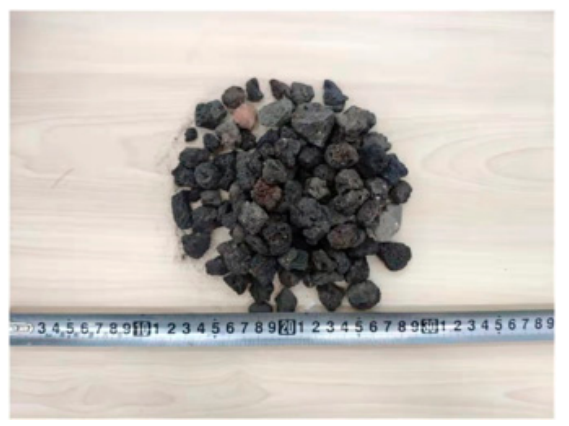

(a)

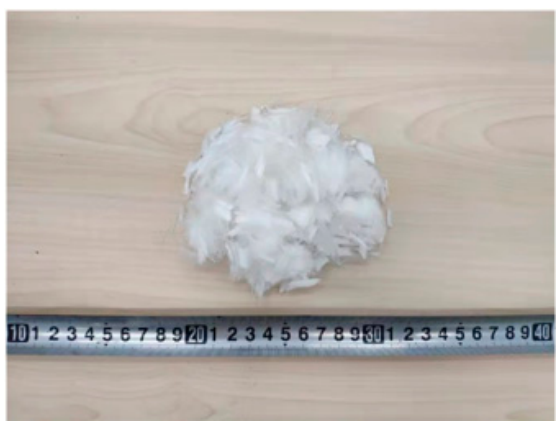

(b)

Figure 1. Materials: (a) Scoria aggregate, (b) PP fiber.

In this paper, three tests were conducted: cube compressive strength, splitting tensile strength, and the axial compressive strength of prismatic with dimensions of $100 \mathrm{~mm} \times$ $100 \mathrm{~mm} \times 300 \mathrm{~mm}$. A test procedure similar to [29-33] was used. The test specimens for three groups of tests need to be heated to $20,200,400,600$, and $800{ }^{\circ} \mathrm{C}$. Therefore, a total of 45 specimens of Scoria aggregate concrete and 45 specimens of normal concrete were made for comparison. The prepared test block was placed at room temperature for $24 \mathrm{~h}$ and then demolded and cured at $20{ }^{\circ} \mathrm{C}$ with $95 \pm 5 \%$ relative humidity for 28 days.

\subsection{Test Procedure}

All the following tests were performed in the Structures Laboratory of Jilin Jianzhu University, China. The heating equipment was a resistance furnace with a heating rate of $5{ }^{\circ} \mathrm{C} / \mathrm{min}$ and the temperature in the furnace up to $1000^{\circ} \mathrm{C}$. This replicated the standard fire tests [34,35]. After the specimens were heated to $200,400,600$, and $800^{\circ} \mathrm{C}$, the furnace temperature was maintained for $3 \mathrm{~h}$ to ensure that the internal temperature of the specimens also reached the target value.

The compressive strength of the cube specimens was tested by a YAR-2000 hydraulic testing machine with a loading rate of $0.5 \mathrm{MPa} / \mathrm{s}$. The axial compressive strength was obtained. Axial compressive tests were performed on the prismatic blocks using a Type YAW-5000 electrohydraulic servo universal testing machine. The testing machine applied load through displacement control and set the loading rate to $0.1 \mathrm{~mm} / \mathrm{min}$. The stress was controlled by the test machine, and the strain was measured by DIC. The stress-strain curve was then plotted. The test machine is shown in Figure 2.

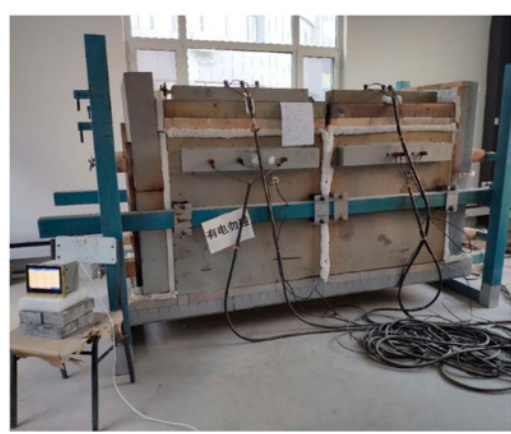

(a)

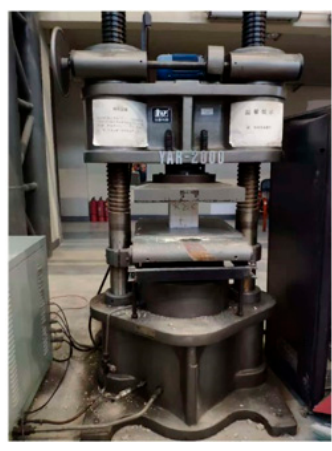

(b)

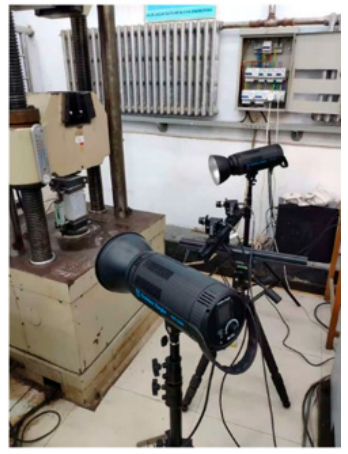

(c)

Figure 2. Testing machine: (a) Resistance furnace, (b) Hydraulic pressure testing machine, (c) DIC.

DIC is a noncontact deformation test method in which marking spots are randomly scattered on a specimen surface, and the changes in the relative positions of these scatter spots during the loading process are compared. The displacement field on the specimen surface was calculated to obtain the strain distribution field for further analysis. A high- 
speed camera with a resolution of $1280 \times 800$ was used for image acquisition. The power of the dimmable LED lamp was $1000 \mathrm{~W}$. The camera was placed symmetrically with the fill light, and the specimen surface with all the scatter spots was placed in the center of the visible range of the camera. The camera was used to photograph the prismatic axial pressure test at a frequency of one photograph per second. The photographs were acquired and analyzed using DIC software to obtain the vertical displacement and transverse strain clouds of the specimen.

\section{Test Results and Discussion}

\subsection{Failure Mode}

\subsubsection{Color Changes}

Figure 3 shows the changes in the color and the surface cracks of NC and SAC after exposure to different high temperatures. The specimens changed to yellowish gray, brownish-gray, brown, and whitish gray after being subjected to high temperatures of 200, 400,600 and $800{ }^{\circ} \mathrm{C}$, respectively. Temperatures of 800 and $600{ }^{\circ} \mathrm{C}$ produced significantly different color changes in the specimens. The Scoria aggregate concrete specimens with PP fibers exhibited fewer surface cracks and less edge bursting after exposure to $800^{\circ} \mathrm{C}$. This result may have occurred because the PP fibers melted at $160^{\circ} \mathrm{C}$, forming channels through which vapor could diffuse outward and thereby reduce the vapor pressure inside the concrete. These channels were effective in preventing bursting phenomena when the temperature did not exceed $800{ }^{\circ} \mathrm{C}$. PP fibers have a melting point of approximately $160{ }^{\circ} \mathrm{C}$ and were therefore visible inside the specimens at room temperature. When the fire temperature reached $400{ }^{\circ} \mathrm{C}$, the PP fibers inside the specimens disappeared.

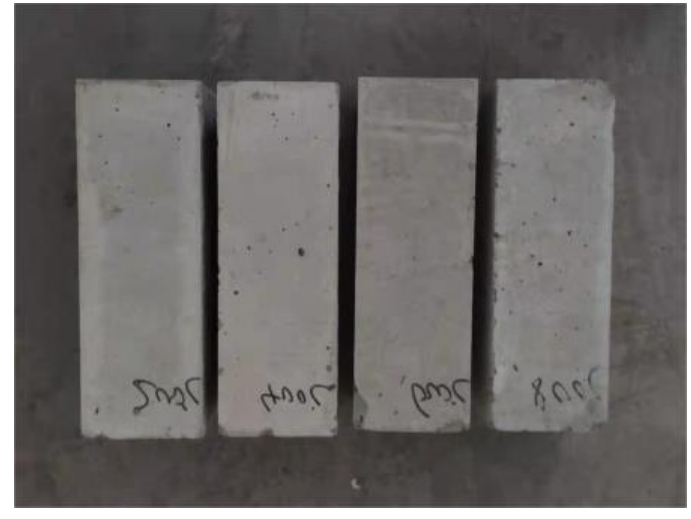

(a)

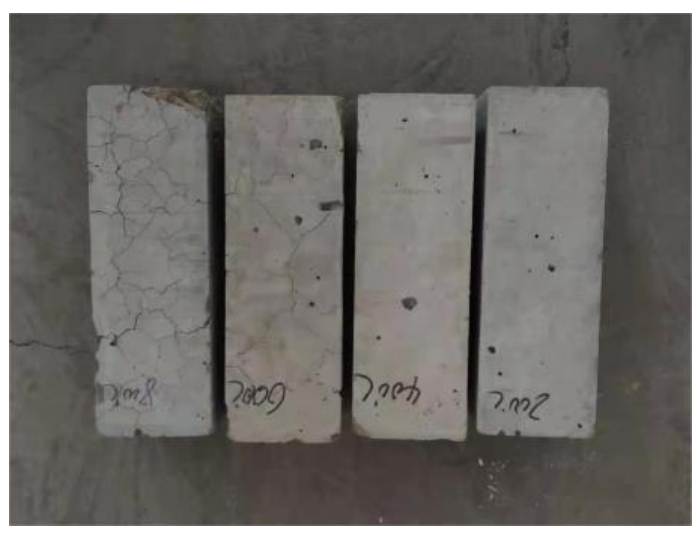

(b)

Figure 3. The changes in the color and surface cracks of specimens after high temperatures: (a) SAC, (b) NC.

\subsubsection{Cracking Behavior}

Figure 4 shows the maximum crack width on the test block surface after hightemperature treatment, as measured by a fracture-width tester. The maximum crack of Scoria aggregate concrete at $800{ }^{\circ} \mathrm{C}$ is $0.301 \mathrm{~mm}$, which is 4.43 times higher than that at $200{ }^{\circ} \mathrm{C}$. The maximum crack of normal concrete at $800{ }^{\circ} \mathrm{C}$ is $0.562 \mathrm{~mm}$, which is 5.11 times higher than that at $200^{\circ} \mathrm{C}$. The maximum crack width for normal concrete was up to 1.87 times greater than that of the Scoria aggregate concrete.

Figure 5 shows similar patterns of diagonal shear cracking and splitting cracking for the uniaxial compressive damage to the Scoria aggregate concrete specimens treated at different temperatures. The specimens were in the elastic stage at the beginning of loading. The load and displacement increased linearly, and there were no noticeable features on the specimen surfaces. As the load increased, internal microcracks gradually formed, and the specimen stiffness began to decrease. The load increased to a peak, beyond which cracks parallel to the force direction appeared on the surface of the specimens. When 
the load was reduced to $60-70 \%$ of the peak load, the axial deformation of the concrete block continued to increase and eventually resulted in the destruction of the specimens. The Scoria aggregate concrete specimens showed more noticeable brittle damage than the conventional concrete specimens, with fewer cracks on the specimen surface and less transverse deformation.

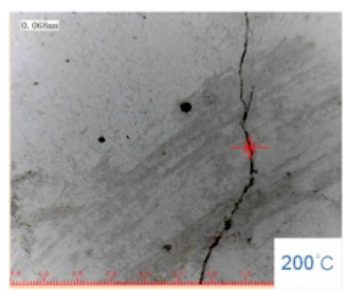

$0.068 \mathrm{~mm}$

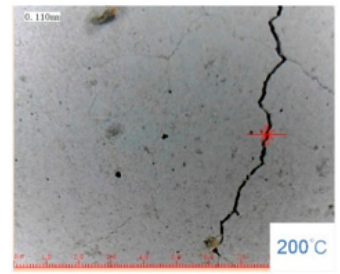

$0.110 \mathrm{~mm}$

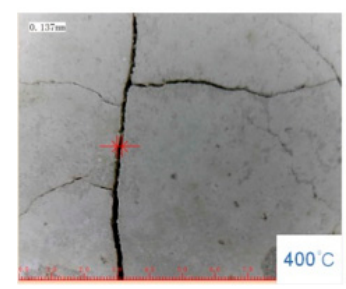

$0.137 \mathrm{~mm}$

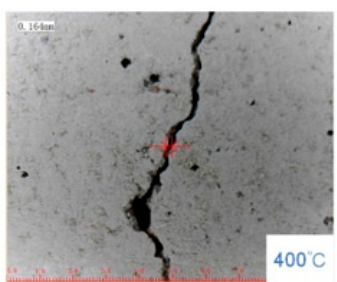

$0.164 \mathrm{~mm}$

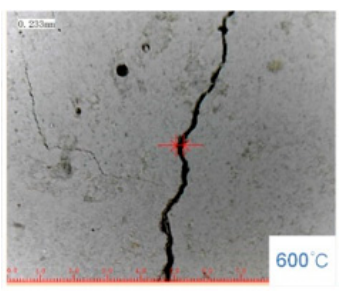

$0.233 \mathrm{~mm}$

(a)

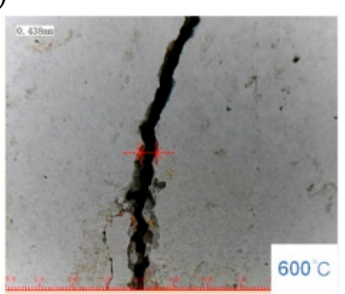

$0.438 \mathrm{~mm}$

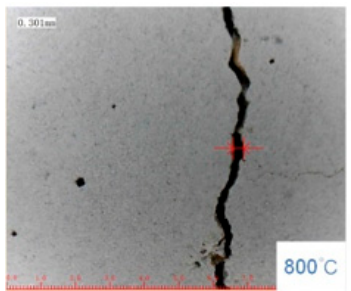

$0.301 \mathrm{~mm}$

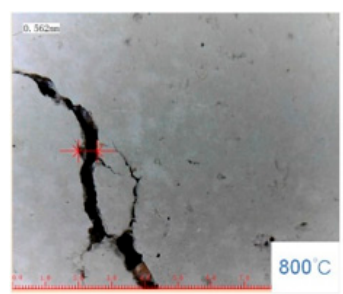

$0.562 \mathrm{~mm}$

(b)

Figure 4. Maximum crack on the surface of specimens after high temperature: (a) SAC, (b) NC.

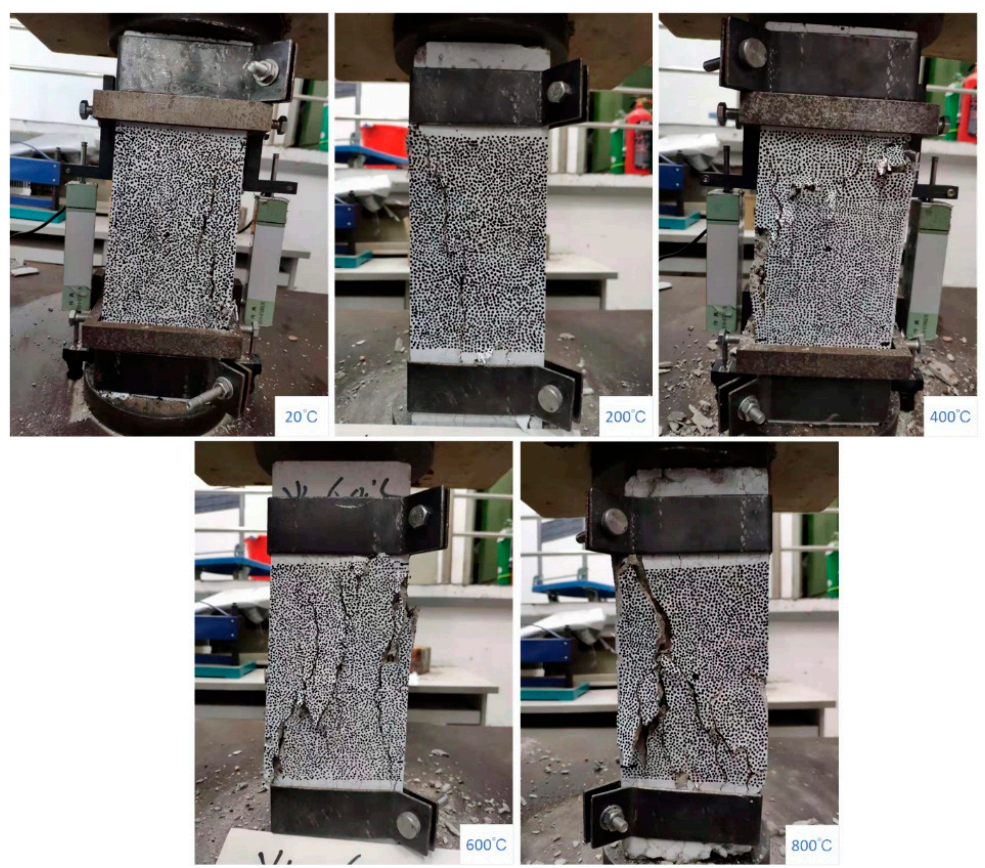

Figure 5. Destruction mode of SAC at different temperatures.

\subsection{Residual Strength}

By testing the compressive strength and splitting tensile strength of concrete specimens treated at different temperatures, it was concluded that the strength of Scoria aggregate concrete decreases with increasing temperature. The effects of temperature on the compressive strength and the strength reduction coefficients of Scoria aggregate concrete are shown in Table 2. 
Table 2. Compression strength of specimens after high temperature.

\begin{tabular}{ccccc}
\hline \multirow{2}{*}{$\left({ }^{\circ} \mathbf{C}\right)$} & \multicolumn{2}{c}{ Compression Strength (Mpa) } & \multicolumn{2}{c}{ Strength Reduction } \\
\cline { 2 - 5 } & SAC & NC & SAC & NC \\
\hline 20 & 41.66 & 39.95 & 1 & 1 \\
200 & 37.33 & 34.25 & 0.89 & 0.86 \\
400 & 34.83 & 32.67 & 0.84 & 0.82 \\
600 & 20.74 & 17.66 & 0.5 & 0.44 \\
800 & 11.1 & 8.09 & 0.27 & 0.2 \\
\hline
\end{tabular}

The reduction in compressive strength of Scoria aggregate concrete specimens below $400{ }^{\circ} \mathrm{C}$ was relatively low, and the compressive strength reduced to 89 and $84 \%$ of that at room temperature. However, the reduction in compressive strength of specimens above $400{ }^{\circ} \mathrm{C}$ was relatively large and the compressive strength reduced to 50 and $27 \%$ of that at room temperature. This result was obtained because the hydration products in the specimens gradually decomposed after $450{ }^{\circ} \mathrm{C}$, and the thermal mismatch between cement paste and aggregates, resulting in a rapid increase in the number of cracks inside the concrete and a significant decrease in the strength of the specimens. As shown in Figure 6, the compressive strength reduction coefficient of the Scoria aggregate concrete at all temperatures was greater than that of normal concrete, which indicated that the effect of high temperature on the compressive strength of the Scoria aggregate concrete was smaller. The data in Table 2 were fitted to obtain Equations (1) and (2) for the residual axial compressive strengths of SAC and NC after high-temperature treatment.

$$
\begin{aligned}
f_{\mathrm{cs}, \mathrm{T}} / f_{\mathrm{cs}}= & 0.9872+0.005142\left(\frac{T}{100}\right)-0.0169\left(\frac{T}{100}\right)^{2} \\
& +0.0006114\left(\frac{T}{100}\right)^{3} 20{ }^{\circ} \mathrm{C} \leq T \leq 800{ }^{\circ} \mathrm{C} \\
f_{\mathrm{cn}, \mathrm{T}} / f_{\mathrm{cn}}= & 0.9865-0.006324\left(\frac{T}{100}\right)-0.01573\left(\frac{T}{100}\right)^{2} \\
& +0.0005038\left(\frac{T}{100}\right)^{3} 20^{\circ} \mathrm{C} \leq T \leq 800{ }^{\circ} \mathrm{C}
\end{aligned}
$$

where $f_{\mathrm{cs}, \mathrm{T}}$ and $f_{\mathrm{cs}}$ are the axial compressive strength of SAC at high temperature and at room temperature, respectively $(\mathrm{MPa}) ; f_{\mathrm{cn}, \mathrm{T}}$ and $f_{\mathrm{cn}}$ are the axial compressive strength of NC at high temperature and at room temperature, respectively (MPa); and $T$ is the temperature, ${ }^{\circ} \mathrm{C}$. The $R^{2}$ value in Equation (1) is 0.957. The $R^{2}$ value in Equation (2) is 0.946.

The splitting tensile strengths of the Scoria aggregate concrete after high temperature and its strength reduction coefficients are shown in Table 3. The splitting tensile strength of the Scoria aggregate concrete specimens decreased with increasing temperature to 84, 73, 37 , and $22 \%$ of the splitting tensile strength at room temperature. Similarly, Figure 7 shows that the splitting tensile strength reduction coefficient of the Scoria aggregate concrete was greater than that of normal concrete at all temperatures. Equations (3) and (4) for the residual axial splitting tensile strength of the specimen were similarly obtained by curve fitting.

$$
\begin{aligned}
f_{\mathrm{ts}, \mathrm{T}} / f_{\mathrm{ts}}= & 0.9902-0.009663\left(\frac{T}{100}\right)-0.02479\left(\frac{T}{100}\right)^{2} \\
& +0.001725\left(\frac{T}{100}\right)^{3} 20{ }^{\circ} \mathrm{C} \leq T \leq 800{ }^{\circ} \mathrm{C} \\
f_{\mathrm{tn}, \mathrm{T}} / f_{\mathrm{tn}}= & 1.009-0.1383\left(\frac{T}{100}\right)+0.01342\left(\frac{T}{100}\right)^{2} \\
& -0.001301\left(\frac{T}{100}\right)^{3} 20{ }^{\circ} \mathrm{C} \leq T \leq 800{ }^{\circ} \mathrm{C}
\end{aligned}
$$

where $f_{\mathrm{ts}, \mathrm{T}}$ and $f_{\mathrm{ts}}$ are the splitting tensile strength of SAC at high temperature and at room temperature, respectively $(\mathrm{MPa}) ; f_{\mathrm{tn}, \mathrm{T}}$ and $f_{\mathrm{tn}}$ are the splitting tensile strength of $\mathrm{NC}$ at high temperature and at room temperature, respectively (MPa), and the $R^{2}$ value in Equation (3) is 0.961 . The $R^{2}$ value in Equation (4) is 0.931 . 


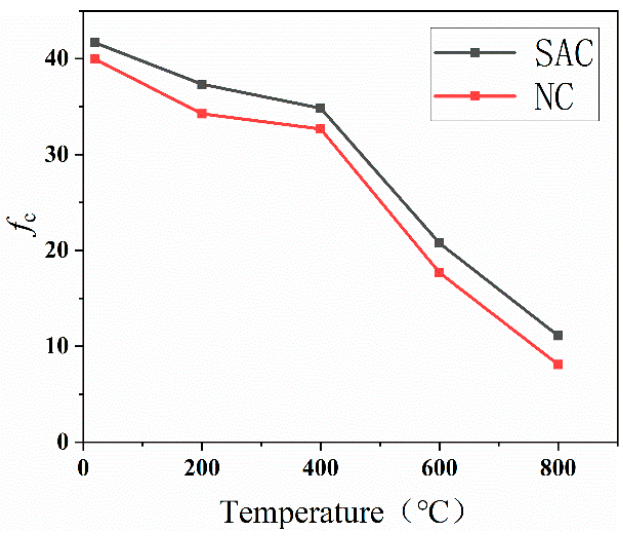

(a)

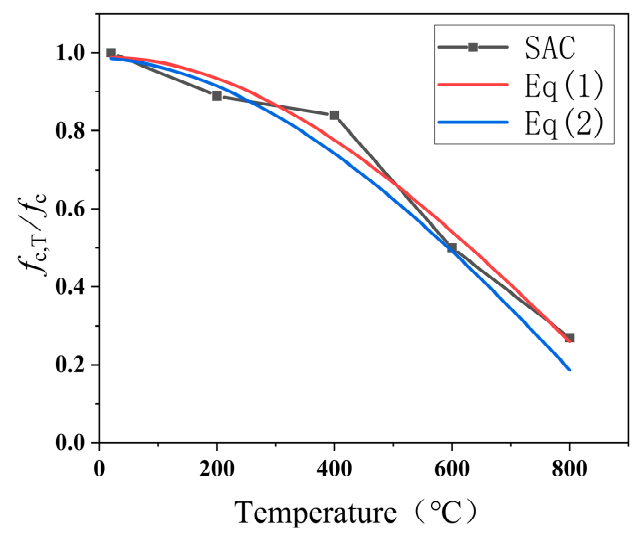

(b)

Figure 6. (a) Reduction of compressive strength. (b) Relative reduction of compressive strength.

Table 3. Splitting tensile strength of specimens after high temperature.

\begin{tabular}{ccccc}
\hline \multirow{2}{*}{$\left({ }^{\circ} \mathbf{C}\right)$} & \multicolumn{2}{c}{ Splitting Tensile Strength (Mpa) } & \multicolumn{2}{c}{ Strength Reduction } \\
\cline { 2 - 5 } & SAC & NC & SAC & NC \\
\hline 20 & 2.69 & 2.02 & 1 & 1 \\
400 & 2.26 & 1.44 & 0.84 & 0.71 \\
600 & 1.96 & 1.37 & 0.73 & 0.68 \\
800 & 1 & 0.65 & 0.37 & 0.32 \\
\hline
\end{tabular}

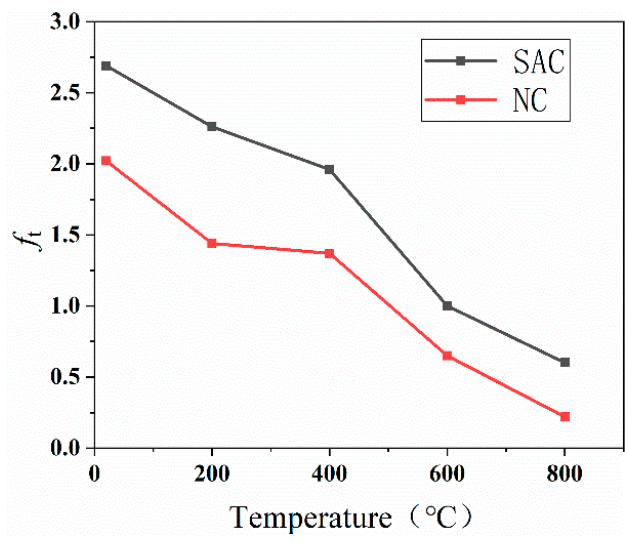

(a)

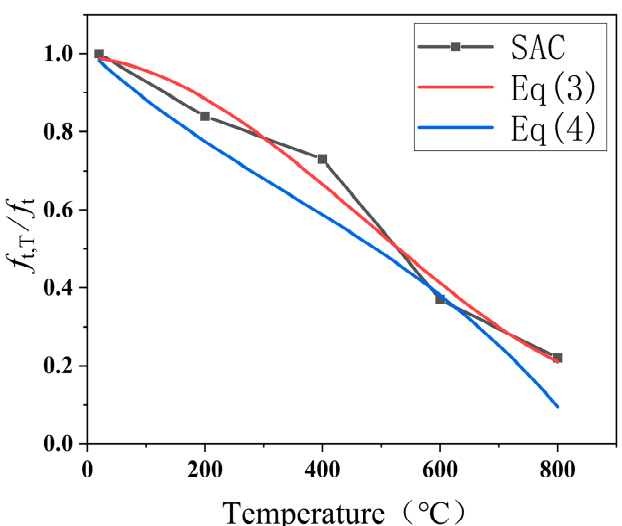

(b)

Figure 7. Splitting tensile strength. (a) Reduction of splitting tensile strength. (b) Relative reduction of splitting tensile strength.

\subsection{Stress-Strain Relationship of Scoria Aggregate Concrete}

\subsubsection{Strain Distribution Analysis of DIC}

Figure 8 shows the strain distribution from the DIC image of the peak strain and $80 \%$ peak strain of the Scoria aggregate concrete at different temperatures. It can be seen that the strain values gradually increased as the temperature increased. As shown in Figure 8b, for the specimen with the lower temperature, when the peak strain was reached, only the transverse strain concentration zone appeared at the bottom of the specimen, and no cracks appeared in the middle of the specimen. For the specimens subjected to higher temperatures, when the peak strain was reached, transverse strain concentration zones appeared at the top and bottom of the specimens, and these strain concentration zones were connected to form cracks, leading to damage of the specimen. The cracks were consistent with the failure mode of the test block in Figure 5, mainly diagonal shear cracking and splitting cracking, as shown in Figure $8 \mathrm{~h}$. 


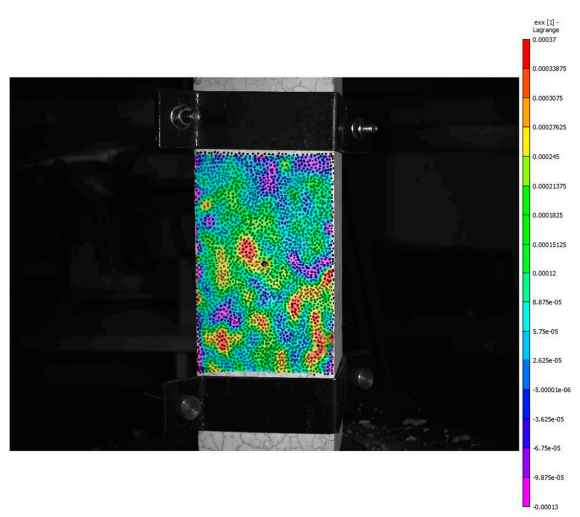

(a)

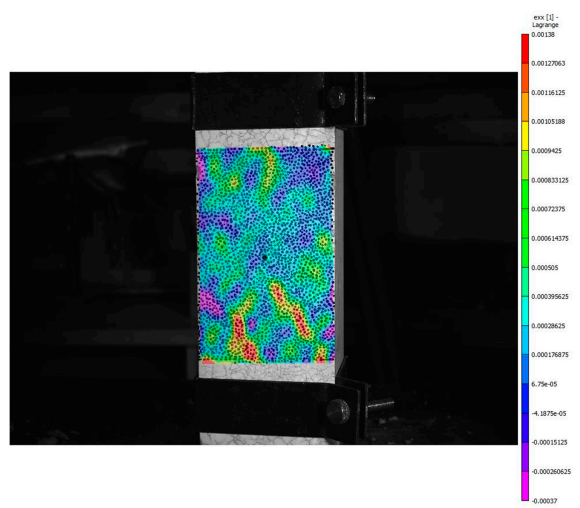

(c)

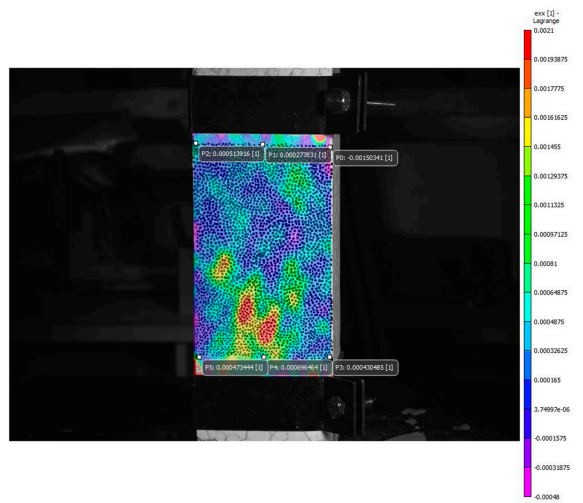

(e)

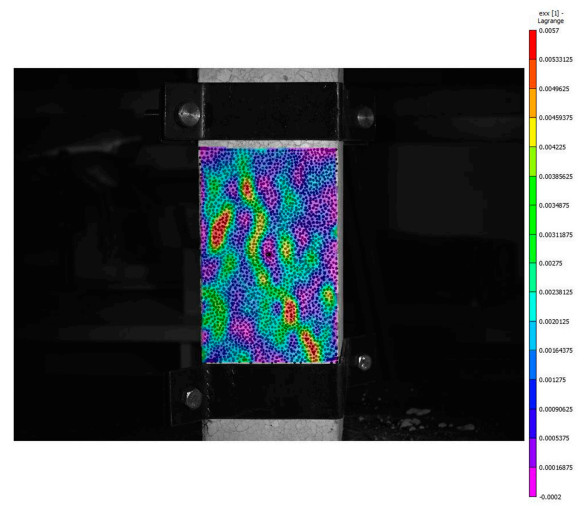

(g)

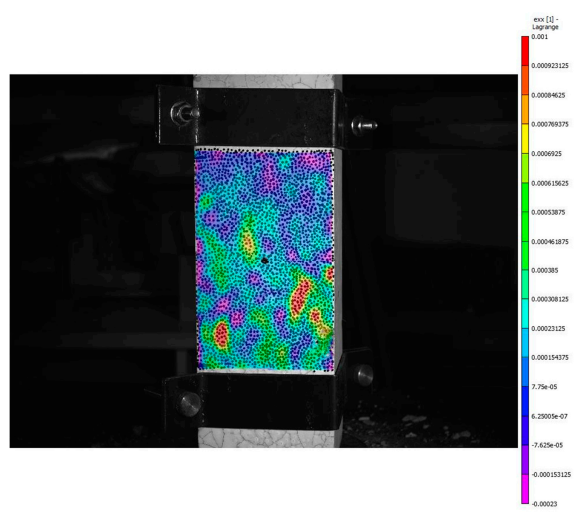

(b)

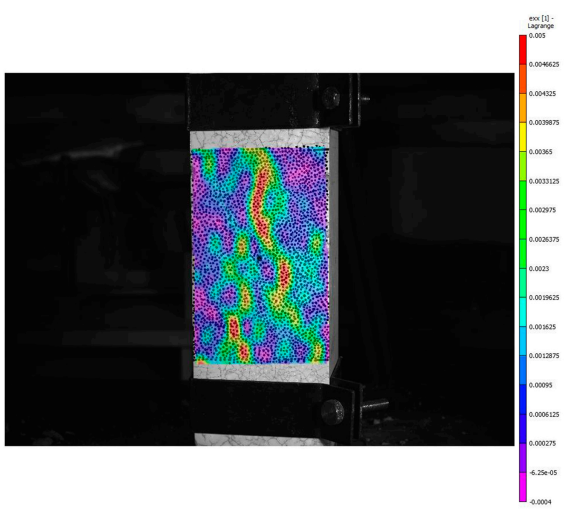

(d)

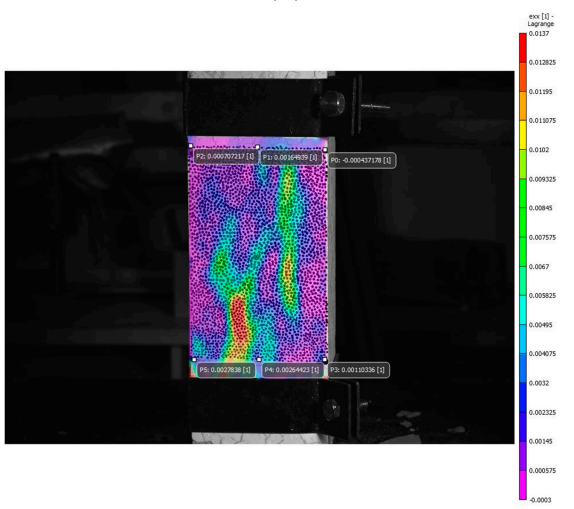

(f)

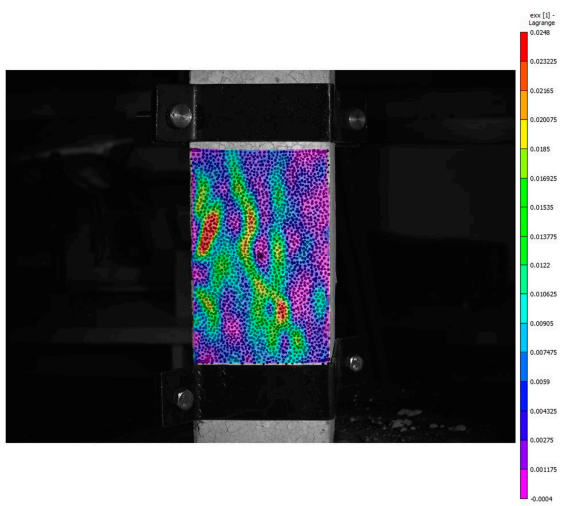

(h)

Figure 8. Strain nephogram of SAC: (a) $200{ }^{\circ} \mathrm{C} 80 \%$ peak strain; (b) $200{ }^{\circ} \mathrm{C}$ peak strain; (c) $400{ }^{\circ} \mathrm{C}$ $80 \%$ peak strain; (d) $400{ }^{\circ} \mathrm{C}$ peak strain; (e) $600{ }^{\circ} \mathrm{C} 80 \%$ peak strain; (f) $600{ }^{\circ} \mathrm{C}$ peak strain; (g) $800{ }^{\circ} \mathrm{C}$ $80 \%$ peak strain; $\left(\right.$ h) $800{ }^{\circ} \mathrm{C}$ peak strain. 


\subsubsection{Peak Strain}

As shown in Table 4, the peak strains of both normal concrete and Scoria aggregate concrete increased with increasing temperature. However, the change in the peak strain of the Scoria aggregate concrete after high-temperature treatment was smaller than that of normal concrete. The difference between the two peak strains increased significantly above $400{ }^{\circ} \mathrm{C}$. The peak strains of normal concrete after exposure to high temperatures were 5.42 and 5.97 times greater than those at room temperature, while the peak strains of the Scoria aggregate concrete after high temperatures were 1.9 and 3.11 times greater than those at room temperature. The excellent fire resistance of the Scoria aggregate concrete specimens resulted in fewer cracks and a smaller peak strain compared to the conventional concrete. The effect of temperature on peak strain is shown in Figure 9. Equations (5) and (6) for the relative peak strain of the specimen were similarly obtained by curve fitting.

$$
\begin{aligned}
& \varepsilon_{\mathrm{cps}, \mathrm{T}} / \varepsilon_{\mathrm{cps}}= 0.9874-0.08143\left(\frac{T}{100}\right)+0.03687\left(\frac{T}{100}\right)^{2} \\
&+ 0.0007655\left(\frac{T}{100}\right)^{3} 20{ }^{\circ} \mathrm{C} \leq T \leq 800{ }^{\circ} \mathrm{C} \\
& \varepsilon_{\mathrm{cpn}, \mathrm{T}} / \varepsilon_{\mathrm{cpn}} \quad=1.4-1.599\left(\frac{T}{100}\right)+0.6556\left(\frac{T}{100}\right)^{2} \\
&- 0.04786\left(\frac{T}{100}\right)^{3} 20^{\circ} \mathrm{C} \leq T \leq 800^{\circ} \mathrm{C}
\end{aligned}
$$

where $\varepsilon_{\mathrm{cps}, \mathrm{T}}$ and $\varepsilon_{\mathrm{cps}}$ are the peak strain of SAC at high temperature and at room temperature, respectively $(\mathrm{MPa}) ; \varepsilon_{\mathrm{cpn}, \mathrm{T}}$ and $\varepsilon_{\mathrm{cpn}}$ are the peak strain of $\mathrm{NC}$ at high temperature and at room temperature, respectively (MPa); and the $R^{2}$ value in Equation (5) is 0.9763 . The $R^{2}$ value in Equation (6) is 0.954.

Table 4. Peak strain of specimens after high temperature.

\begin{tabular}{ccccc}
\hline \multirow{2}{*}{$\boldsymbol{T}\left({ }^{\circ} \mathbf{C}\right)$} & \multicolumn{2}{c}{ Peak Strain } & \multicolumn{2}{c}{ Relative Peak Strain } \\
\cline { 2 - 5 } & SAC & NC & SAC & Equation (3) \\
\hline 20 & 0.00187 & 0.001887 & 1 & 0.9786 \\
200 & 0.001646 & 0.001551 & 0.88 & 0.9781 \\
400 & 0.002683 & 0.003564 & 1.44 & 1.301 \\
600 & 0.003549 & 0.010222 & 1.9 & 1.991 \\
800 & 0.005809 & 0.011266 & 3.11 & 3.088 \\
\hline
\end{tabular}

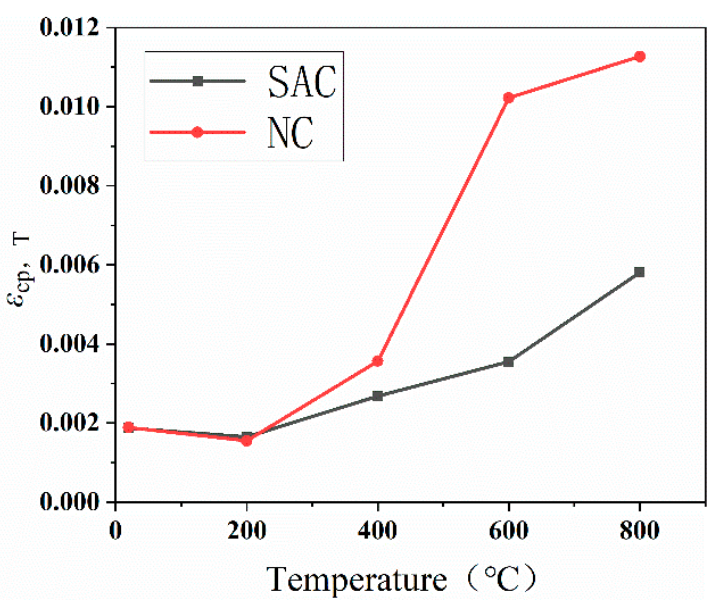

(a)

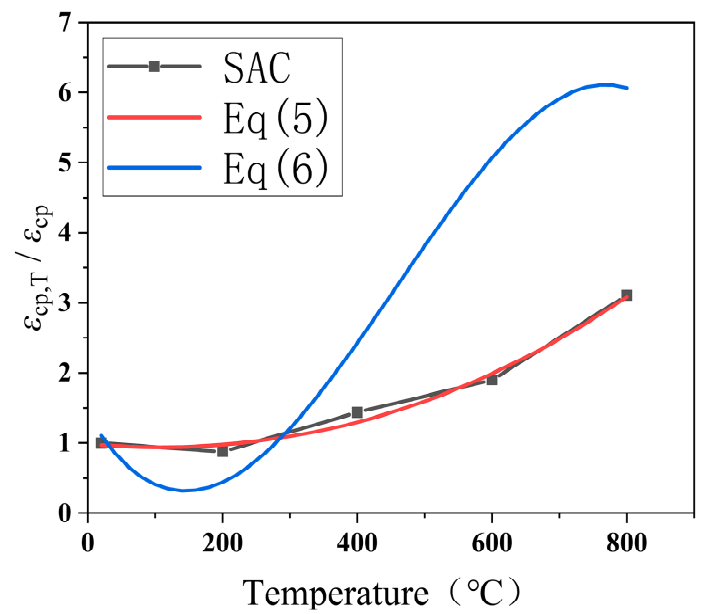

(b)

Figure 9. Peak strain of specimens after high temperature: (a) Peak strain, (b) Relative peak strain. 


\subsubsection{Secant Modulus}

In this paper, the secant modulus corresponding to the rising section of the stress-strain curve of concrete after high temperature from the origin to the $40 \%$ peak stress point was taken as the elasticity modulus. Table 5 shows that the secant modulus of the specimens decreased with different degrees of temperature increase, but the secant modulus of Scoria aggregate concrete specimens at different temperatures was greater than that of ordinary concrete. The secant modulus for the Scoria aggregate concrete specimens treated at 200, 400,600 , and $800{ }^{\circ} \mathrm{C}$ was approximately $70,30,13.6$, and $3.5 \%$ of the secant modulus of the unheated concrete, respectively. The decreasing trend is shown in Figure 10. Equations (7) and (8) for the relative secant modulus of the specimen were obtained by curve fitting.

$$
\begin{aligned}
S_{\mathrm{cs}, \mathrm{T}} / S_{\mathrm{cs}}= & 1.045-0.1864\left(\frac{T}{100}\right)-0.002428\left(\frac{T}{100}\right)^{2} \\
& +0.001255\left(\frac{T}{100}\right)^{3} 20{ }^{\circ} \mathrm{C} \leq T \leq 800{ }^{\circ} \mathrm{C} \\
S_{\mathrm{cn}, \mathrm{T}} / S_{\mathrm{cn}} & =1.04-0.1499\left(\frac{T}{100}\right)-0.02559\left(\frac{T}{100}\right)^{2} \\
& +0.003537\left(\frac{T}{100}\right)^{3} 20^{\circ} \mathrm{C} \leq T \leq 800^{\circ} \mathrm{C}
\end{aligned}
$$

where $S_{\mathrm{cs}, \mathrm{T}}$ and $S_{\mathrm{cs}}$ are the secant modulus of SAC at high temperature and at room temperature, respectively $(\mathrm{MPa}) ; S_{\mathrm{cn}, \mathrm{T}}$ and $S_{\mathrm{cn}}$ are the secant modulus of $\mathrm{NC}$ at high temperature and at room temperature, respectively (MPa), and the $R^{2}$ value in Equation (7) is 0.9908 . The $R^{2}$ value in Equation (8) is 0.989 .

Table 5. Secant modulus of specimens after high temperature.

\begin{tabular}{ccccc}
\hline \multirow{2}{*}{$\left({ }^{\circ} \mathbf{C}\right)$} & \multicolumn{2}{c}{ Residual Secant Modulus } & \multicolumn{2}{c}{ Relative Residual Secant Modulus } \\
\cline { 2 - 5 } & SAC & NC & SAC & Equation (4) \\
\hline 20 & 57,851 & 33,898 & 1 & 1.0076 \\
200 & 40,441 & 23,691 & 0.7 & 0.6725 \\
400 & 17,456 & 7100 & 0.302 & 0.341 \\
600 & 7861 & 499 & 0.136 & 0.11 \\
800 & 2039 & 229 & 0.035 & 0.0212 \\
\hline
\end{tabular}

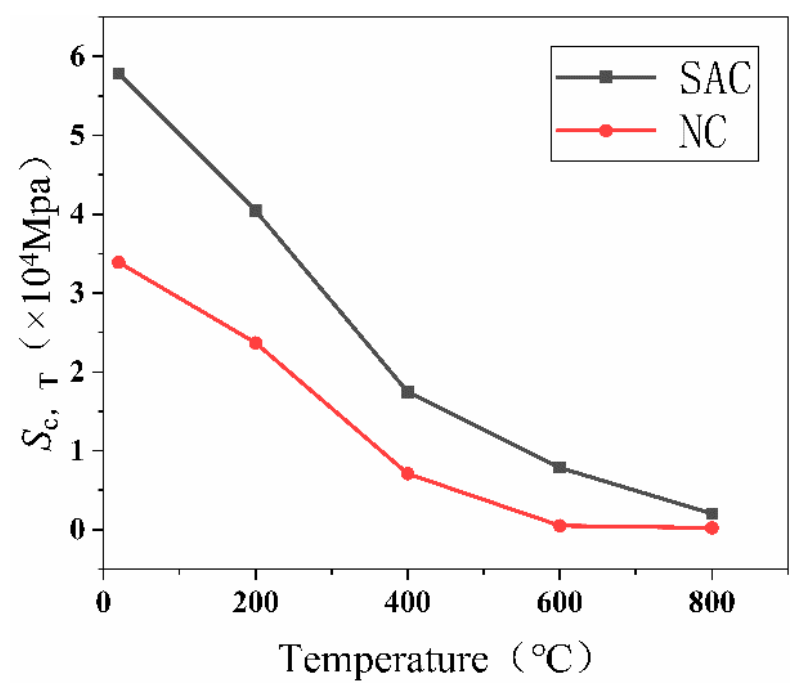

(a)

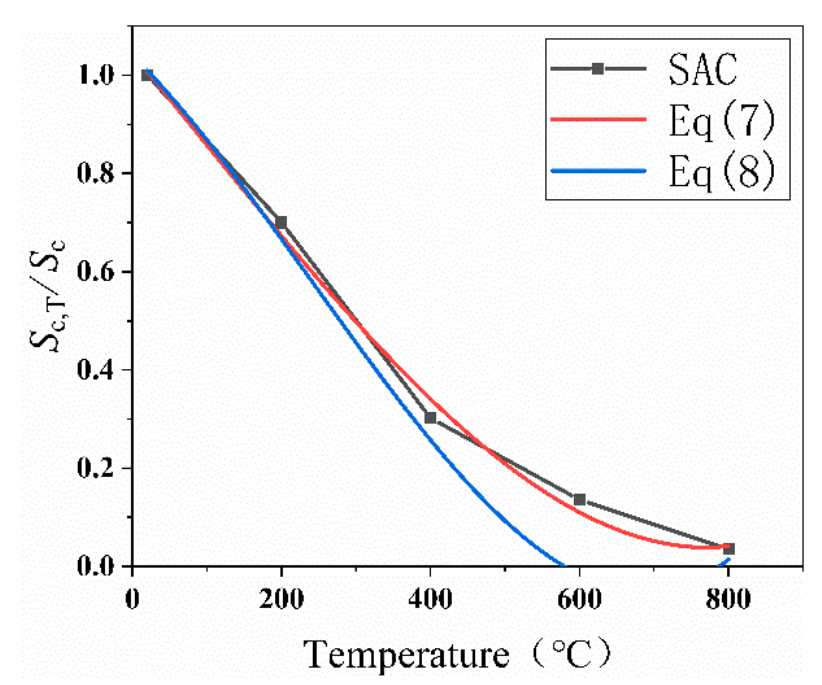

(b)

Figure 10. Secant modulus of specimens after high temperature: (a) Residual secant modulus. (b) Relative residual secant modulus. 


\subsubsection{Ultimate Strain}

The descending section of the stress-strain curve was used to determine the ultimate strain of concrete, corresponding to the strain at the $0.5 f_{\text {cr }}$ stress value. The ultimate strain of the specimens after high-temperature treatment is shown in Table 6. The ultimate strain of the concrete increased with temperature, and the amplitude of the variation increased for temperatures above $400{ }^{\circ} \mathrm{C}$. The ultimate strains of the Scoria aggregate concrete specimens subjected to temperatures above $400{ }^{\circ} \mathrm{C}$ were 4.24 and 7.4 times greater than those at room temperature, where the relationship between the temperature and the ultimate strain are shown in Figure 11. Although the ultimate strain reduction coefficient of Scoria aggregate concrete was greater than that of normal concrete, the ultimate strain of Scoria aggregate concrete was still smaller than that of normal concrete even when the temperature reached $800{ }^{\circ} \mathrm{C}$ because the ultimate strain of Scoria aggregate concrete was very small at room temperature. Equations (9) and (10) for the relative ultimate strain of the specimen were obtained by curve fitting.

$$
\begin{aligned}
\varepsilon_{\text {cus }, \mathrm{T}} / \varepsilon_{\text {cus }} & =1.105-0.5083\left(\frac{T}{100}\right)+0.1971\left(\frac{T}{100}\right)^{2} \\
& -0.004385\left(\frac{T}{100}\right)^{3} 20^{\circ} \mathrm{C} \leq T \leq 800{ }^{\circ} \mathrm{C} \\
\varepsilon_{\text {cun }, \mathrm{T}} / \varepsilon_{\text {cun }} & =1.1-0.6517\left(\frac{T}{100}\right)+0.2525\left(\frac{T}{100}\right)^{2} \\
& -0.01653\left(\frac{T}{100}\right)^{3} 20^{\circ} \mathrm{C} \leq T \leq 800{ }^{\circ} \mathrm{C}
\end{aligned}
$$

where $\varepsilon_{\text {cus,T }}$ and $\varepsilon_{\text {cus }}$ are the ultimate strain of SAC at high temperature and at room temperature, respectively $(\mathrm{MPa}) ; \varepsilon_{\mathrm{cun}, \mathrm{T}}$ and $\varepsilon_{\mathrm{cun}}$ are the ultimate strain of $\mathrm{NC}$ at high temperature and at room temperature, respectively (MPa); and the $R^{2}$ value in Equation (9) is 0.9996 . The $R^{2}$ value in Equation (10) is 0.993 .

Table 6. Ultimate strain of specimens after high temperature.

\begin{tabular}{ccccc}
\hline \multirow{2}{*}{$\boldsymbol{T}\left({ }^{\circ} \mathbf{C}\right)$} & \multicolumn{2}{c}{ Ultimate Strain } & \multicolumn{2}{c}{ Relative Ultimate Strain } \\
\cline { 2 - 5 } & SAC & NC & SAC & Equation (5) \\
\hline 20 & 0.00209 & 0.005243 & 1 & 1.0112 \\
200 & 0.00184 & 0.003438 & 0.88 & 0.842 \\
400 & 0.003959 & 0.008294 & 1.89 & 1.945 \\
600 & 0.008862 & 0.013817 & 4.24 & 4.204 \\
800 & 0.015472 & 0.018866 & 7.4 & 7.41 \\
\hline
\end{tabular}

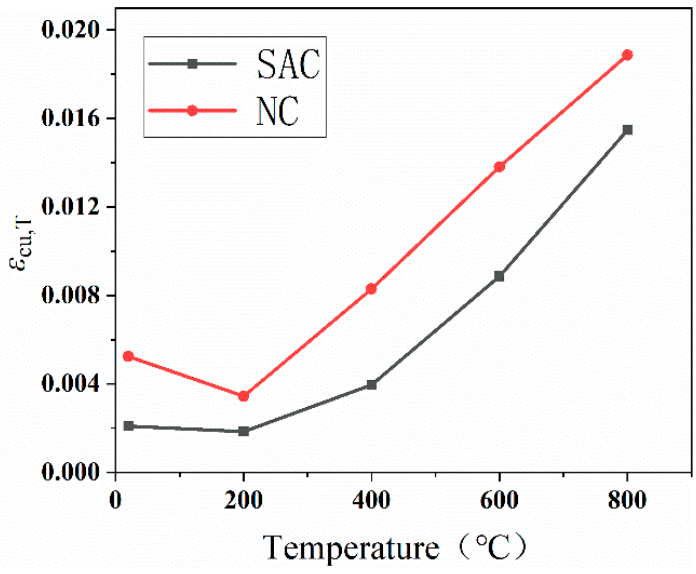

(a)

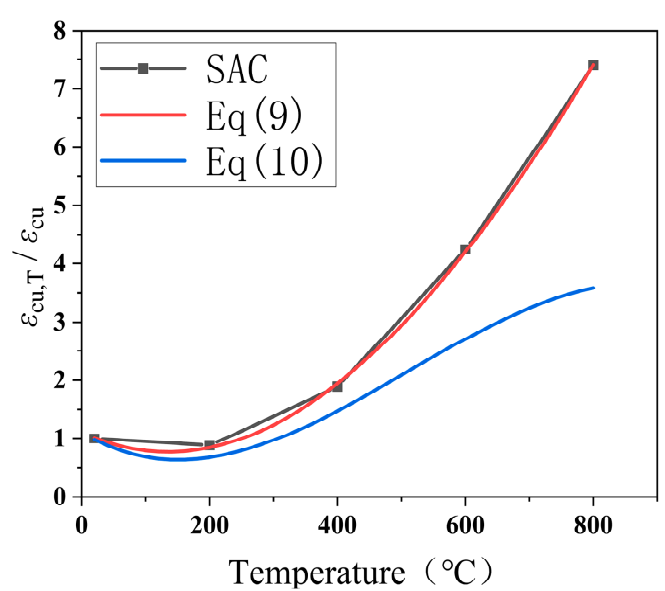

(b)

Figure 11. Ultimate strain of specimens after high temperature: (a) Ultimate strain. (b) Relative ultimate strain. 


\subsubsection{Deformation Capacity}

Different indicators are used in the literature to quantitatively evaluate the deformation capacity of concrete. The ratio of strain at $50 \%$ of the peak stress to the peak strain of concrete $\left(\varepsilon_{\mathrm{cu}} / \varepsilon_{\mathrm{cp}}\right)$ was used to evaluate the deformation capacity of the concrete specimens under the action of axial pressure in this study. The larger the ratio is, the higher the deformation capacity of the specimen is. Figure 12 shows how $\varepsilon_{\mathrm{cu}} / \varepsilon_{\mathrm{cp}}$ varies with temperature. Compared to that of the Scoria aggregate concrete, the deformation capacity of the conventional concrete was higher below $400^{\circ} \mathrm{C}$ and lower (by approximately half) above $600{ }^{\circ} \mathrm{C}$. Thus, the Scoria aggregate concrete performed better and had a more stable structure than the conventional concrete under high-temperature conditions.

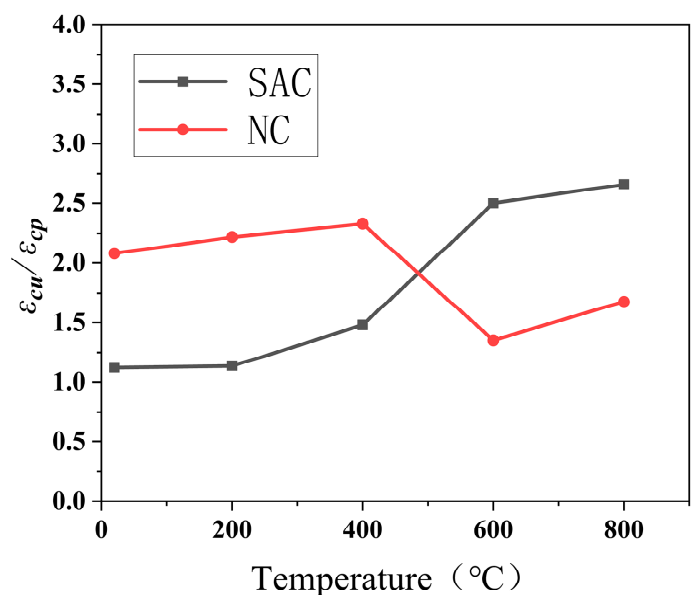

Figure 12. Effect of temperature on $\varepsilon_{\mathrm{cu}} / \varepsilon_{\mathrm{cp}}$.

\section{Development of Constitutive Equations for Scoria Aggregate Concrete}

\subsection{Stress-Strain Curve}

Figure 13 summarizes the axial stress-axial strain curves and axial stress-transverse strain curves of the Scoria aggregate and conventional concrete specimens at different temperatures. Compared to the normal concrete curves, the Scoria aggregate concrete curve has a longer linear ascending section, a steeper descending section (particularly at lower temperatures), and more pronounced brittle damage, which was consistent with the findings of Bing Han [36].

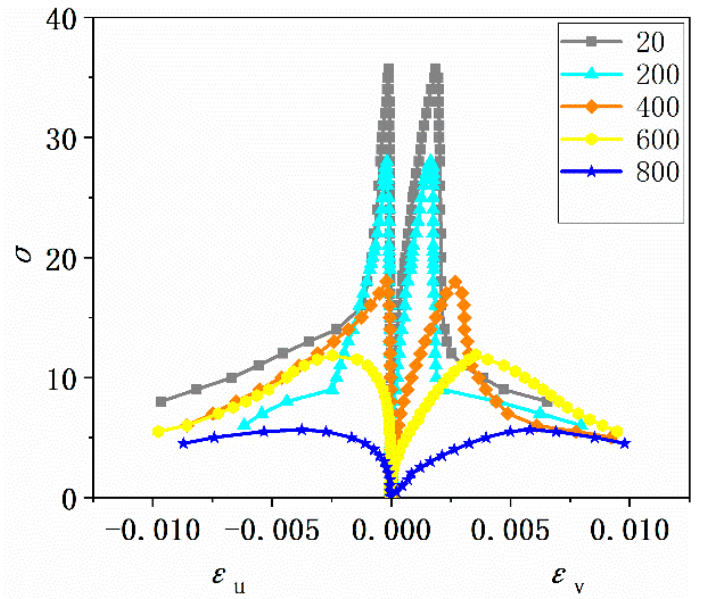

(a)

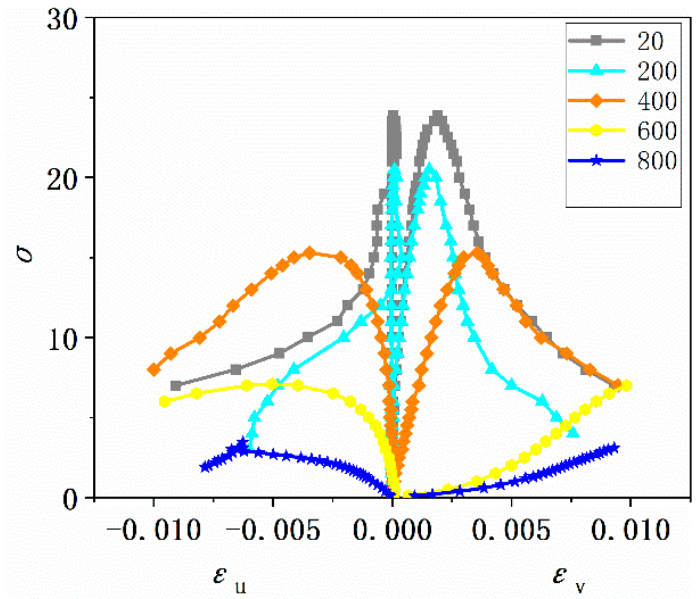

(b)

Figure 13. stress-strain curve of specimens after high temperature: (a) SAC, (b) NC. 
Where $\varepsilon_{\mathrm{u}}$ is the transverse strain of the specimens and $\varepsilon_{\mathrm{V}}$ is the vertical strain of the concrete. The detailed axial stress-strain curves for Scoria aggregate concrete at different fire temperatures are shown in Figure 13b. As the temperature increases, the curve area gradually decreases, and the peak strain moves to the right and increases, whereas the secant modulus decreases sharply. The descending section of the curve is very steep at room temperature, and the curve becomes increasingly flat as the temperature increases. This finding showed that when subjected to high temperatures, Scoria aggregate concrete exhibited better mechanical properties than conventional concrete.

\subsection{Constitutive Equations}

Similar normalized stress-strain curves were obtained for the Scoria aggregate concrete and the conventional concrete, and these curves were divided into four stages, as shown in Figure 14 .

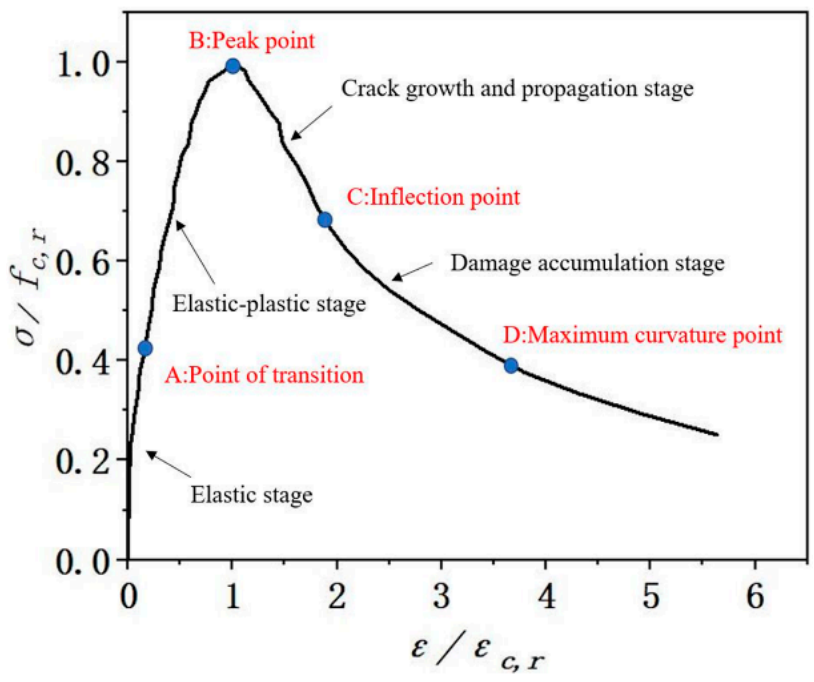

Figure 14. Typical uniaxial compression stress-strain curve of concrete.

Where $\varepsilon_{\mathrm{c}, \mathrm{r}}$ is the peak strain, and $f_{\mathrm{c}, \mathrm{r}}$ is the peak stress. In this study, Equation (11) was adopted from the constitutive relation presented in the Code for Design of Concrete Structures (GB50010-2010). The curve consists of ascending and descending sections, the shapes of which are controlled by the independent parameters $n$ and $\alpha$, respectively. As shown in Equation (12), the parameter $n$ is identified by peak strain, the secant modulus, and peak stress of concrete, and reflects the stress-strain curve characteristics of the rising section of concrete. The parameter $\alpha$ determines the stress-strain curve characteristics of the falling section of concrete. The larger the value of $\alpha$, the steeper the descending section of the stress-strain curve. The change in the magnitude of $\alpha$ value can reflect the changing characteristics of the concrete stress-strain curve. The concrete plastic deformation properties deteriorate as $\alpha$ increases.

$$
\left\{\begin{array}{c}
y=n x / n-1+x^{n} \quad x \leq 1 \\
y=x / \alpha(x-1)^{2}+x \quad x \geq 1
\end{array}\right.
$$

where $x=\varepsilon / \varepsilon_{c, r}, y=\sigma / f_{c, r}$.

$$
n=E_{c} \varepsilon_{c, r} / E_{c} \varepsilon_{c, r}-f_{c, r} .
$$

The experimental data were regressed to obtain $n$ and $\alpha$ for the Scoria aggregate concrete at different fire temperatures. The results are shown in Table 7 . Figure 15 is a comparison of Equations (11) and (12) with the experimental curves that were used to validate the proposed constitutive model. In the ascending phase, the normalized stressstrain curves at different temperatures have nearly the same shape with only slight changes 
in $n$. The descending phase is very steep at lower temperatures, where the Scoria aggregate concrete was brittle and had poor ductility. The $\alpha$ value was large at lower temperatures and gradually decreased as the temperature increased. The $R^{2}$ value reached approximately 0.8 . Thus, the constitutive model effectively reproduced the complete test stress-strain curve.

Table 7. Equation parameters of stress-strain curves of SAC after elevated temperatures.

\begin{tabular}{ccccc}
\hline $\boldsymbol{T}\left({ }^{\circ} \mathrm{C}\right)$ & $\boldsymbol{n}$ & $\boldsymbol{R}^{\mathbf{2}}$ & $\boldsymbol{\alpha}$ & $\boldsymbol{R}^{\mathbf{2}}$ \\
\hline 20 & 1.898 & 0.805 & 49.31 & 0.81 \\
200 & 2.17 & 0.886 & 72.44 & 0.84 \\
400 & 1.827 & 0.78 & 9.993 & 0.79 \\
600 & 2.201 & 0.79 & 1.079 & 0.98 \\
800 & 1.991 & 0.976 & 0.676 & 0.91 \\
\hline
\end{tabular}

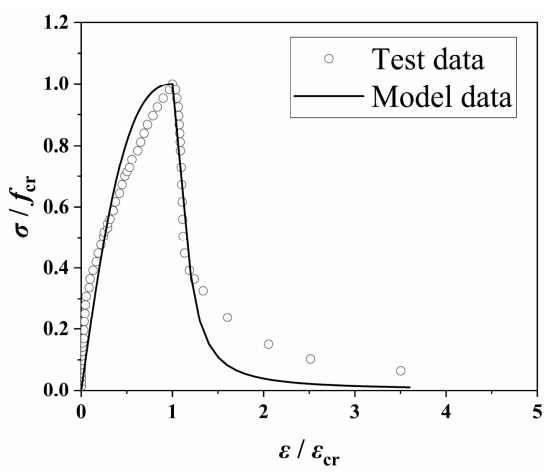

(a)

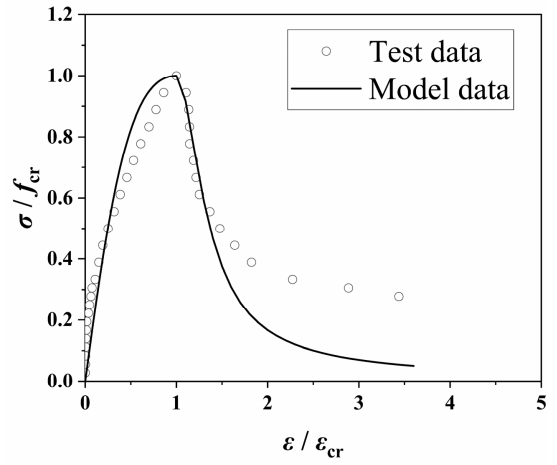

(c)

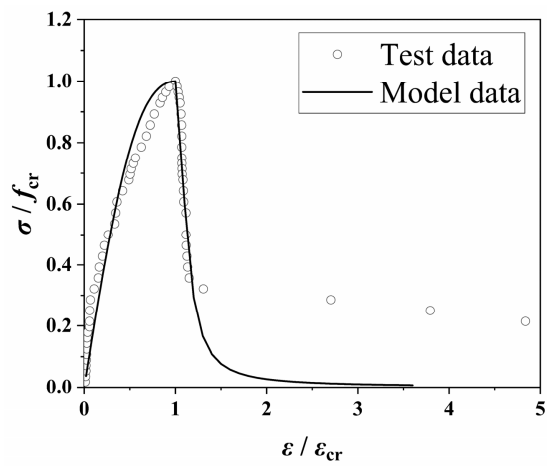

(b)

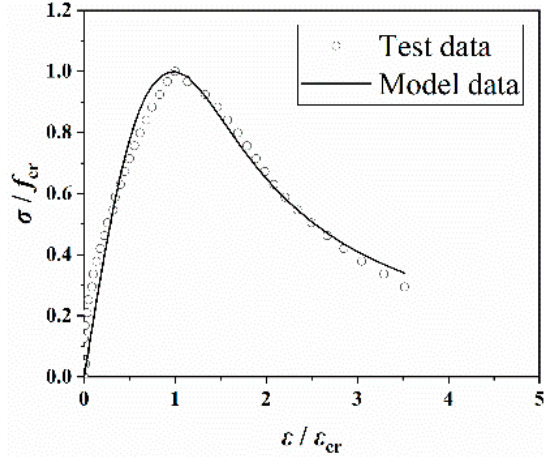

(d)

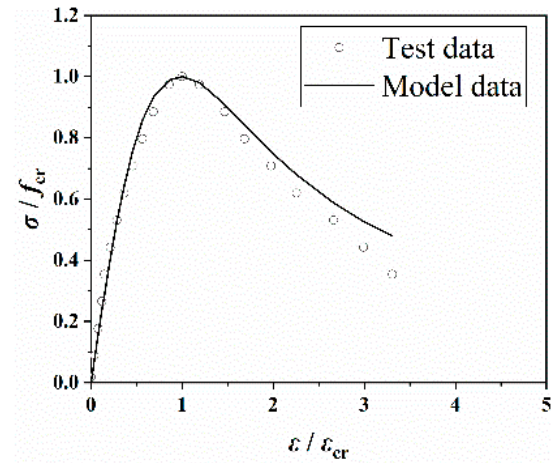

(e)

Figure 15. Comparison between calculated and tested curves of HPLWC after different temperatures: (a) Ambient temperature, (b) $200^{\circ} \mathrm{C}$, (c) $400{ }^{\circ} \mathrm{C}$, (d) $600{ }^{\circ} \mathrm{C}$, (e) $800{ }^{\circ} \mathrm{C}$. 


\section{Conclusions}

After sorting and comparing the data obtained, the following conclusions related to the residual mechanical properties of Scoria aggregate concrete after fire exposure can be made.

(1) The specimens turned yellowish gray, brownish-gray, brown, and whitish gray after being subjected to temperatures of $200,400,600$, and $800{ }^{\circ} \mathrm{C}$, respectively. The incorporation of the PP fibers effectively prevented bursting phenomena when the temperature did not exceed $800^{\circ} \mathrm{C}$.

(2) The effect of temperature on the maximum crack width was significant, with the maximum crack width of $\mathrm{SAC}$ at $800{ }^{\circ} \mathrm{C}$ being 4.43 times that at $200^{\circ} \mathrm{C}$. The maximum crack width of the normal concrete was much larger than that of the PP fiber-reinforced Scoria aggregate concrete, reaching a value that was 1.87 times greater than that of Scoria aggregate concrete at $800{ }^{\circ} \mathrm{C}$.

(3) The temperature significantly affected the damage mode of the PP fiber-reinforced Scoria aggregate concrete. Strength reductions began to increase above $400^{\circ} \mathrm{C}$ (an important demarcation point). After $200^{\circ} \mathrm{C}$, the PP fiber-reinforced Scoria aggregate concrete retained approximately $89 \%$ of its unheated compressive strength, which was further reduced to 50 and $27 \%$ after exposure to temperatures of 600 and $800{ }^{\circ} \mathrm{C}$, respectively.

(4) The compressive strength reduction coefficient of Scoria aggregate concrete at $800^{\circ} \mathrm{C}$ was 0.27 , while the compressive strength reduction coefficient of the normal concrete after $800{ }^{\circ} \mathrm{C}$ was 0.2 . The degradation of the secant modulus caused by high temperatures was more serious than the degradation of the residual strength, and the secant modulus reduction coefficient of Scoria aggregate concrete at $800{ }^{\circ} \mathrm{C}$ was 0.035 , while the secant modulus reduction coefficient of the normal concrete after $800^{\circ} \mathrm{C}$ was 0.021 .

(5) The deformation capacity of the PP fiber-reinforced Scoria aggregate concrete at 600 and $800{ }^{\circ} \mathrm{C}$ was generally better than that of the normal concrete, and at 200 and $400{ }^{\circ} \mathrm{C}$, the deformation capacity of the PP fiber-reinforced Scoria aggregate concrete was lower than that of the normal concrete. However, PP fiber-reinforced Scoria aggregate concrete has better mechanical properties compared to normal concrete at high temperatures.

(6) Mathematical expressions for the full stress-strain curve of Scoria aggregate concrete were established based on $n$ and $\alpha$, and these expressions can be used to numerically simulate the intrinsic structural relationship of Scoria aggregate concrete, as in the present study.

Author Contributions: Conceptualization, B.C. and F.F.; methodology, B.C. and F.F.; test, Y.T.; validation, Y.T.; investigation, Y.T.; resources, B.C.; data curation, B.C.; writing-original draft preparation, Y.T.; writing-review and editing, Y.T.; visualization, B.C.; supervision, B.C.; project administration, B.C.; funding acquisition. All authors have read and agreed to the published version of the manuscript.

Funding: This research was funded by the scientific research projects of the Education Department of Jilin province, grant number JJKH20210279KJ.National Natural Science Foundation of China, 51968013

Conflicts of Interest: The authors declare that they have no competing interests.

\section{References}

1. Ting, T.Z.H.; Rahman, M.E.; Lau, H.H.; Ting, M.Z.Y. Recent development and perspective of lightweight aggregates based self-compacting concrete. Constr. Build. Mater. 2019, 201, 763-777. [CrossRef]

2. Wang, Z.; Li, X.; Jiang, L.; Wang, M.; Xu, Q.; Harries, K. Long-term performance of lightweight aggregate reinforced concrete beams. Constr. Build. Mater. 2020, 264, 120231. [CrossRef]

3. Donglin, Y.; Li, B.; Li, W.; Xia, J.; Zhou, Y. Research and Application of Scoria aggregate Lightweight Aggregate Concrete at Home and Abroad. World Build. Mater. 2017, 38, 26-30.

4. Siddique, R. Properties of concrete made with volcanic ash. Resour. Conserv. Recycl. 2012, 66, 40-44. [CrossRef]

5. Khandaker, M.A. Blended cement using volcanic ash and pumice. Cem. Concr. Res. 2003, 33, 1601-1605.

6. Labbaci, Y.; Abdelaziz, Y.; Mekkaouic, A.; Alouanic, A.; Labbacia, B. The use of the volcanic powders as supplementary cementitious materials for environmental-friendly durable concrete. Constr. Build. Mater. 2017, 133, 468-481. [CrossRef] 
7. Demirdag, S.; Gunduz, L. Strength properties of Scoria aggregate aggregate lightweight concrete for high performance masonry units. Constr. Build. Mater. 2008, 22, 135-142. [CrossRef]

8. Lemougna, P.N.; Wang, K.; Tang, Q.; Nzeukou, A.N.; Billong, N.; Melo, U.C.; Xue-Min, C. Review on the use of volcanic ashes for engineering applications. Resour. Conserv. Recycl. 2018, 137, 177-190. [CrossRef]

9. Tchamdjou, W.H.J.; Cherradi, T.; Pereira-de-Oliveira, L.A. Mechanical properties of lightweight aggregates concrete made with cameroonian volcanic scoria: Destructive and non-destructive characterization. J. Build. Eng. 2018, 16, 134-145. [CrossRef]

10. Abouhussien, A.A.; Hassan, A.A.A.; Ismail, M.K. Properties of semi lightweight self consolidating concrete containing lightweight slag aggregate. Constr. Build. Mater. 2015, 75, 63-73. [CrossRef]

11. Onoue, K.; Tamai, H.; Suseno, H. Shock-absorbing capability of lightweight concrete utilizing volcanic pumice aggregate. Constr Build. Mater. 2015, 83, 261-274. [CrossRef]

12. Bogas, J.A.; Cunha, D. Non-structural lightweight concrete with volcanic scoria aggregates for lightweight fill in building's floors. Constr. Build. Mater. 2017, 135, 151-163. [CrossRef]

13. Al-Swaidani, A.M.; Khwies, W.T. Applicability of Artificial Neural Networks to Predict Mechanical and Permeability Properties of Volcanic Scoria-Based Concrete. Adv. Civ. Eng. 2018, 2018, 5207962. [CrossRef]

14. Arioz, O. Effects of elevated temperatures on properties of concrete. Fire Saf. J. 2007, 42, 516-522. [CrossRef]

15. Wei, H.; Wu, T.; Liu, X.; Zhang, R. Investigation of stress-strain relationship for confined lightweight aggregate concrete. Constr. Build. Mater. 2020, 256, 119432. [CrossRef]

16. Chang, Y.; Chen, Y.; Sheu, M.; Yao, G. Residual stress-strain relationship for concrete after exposure to high temperatures. Cem. Concr. Res. 2006, 36, 1999-2005. [CrossRef]

17. Drozdzol, K. Thermal and Mechanical Studies of Perlite Concrete Casing for Chimneys in Residential Buildings. Materials 2021, 14, 2011. [CrossRef] [PubMed]

18. Alraddadi, S. Surface and thermal properties of fine black and white volcanic ash. Mater. Today Proc. 2020, 26 Pt 2, $1964-1966$. [CrossRef]

19. Khandaker, M.; Hossain, A. High strength blended cement concrete incorporating volcanic ash: Performance at high temperatures. Cem. Concr. Compos. 2006, 28, 535-545.

20. Baloch, W.L.; Khushnood, R.A.; Memon, S.A.; Ahmed, W.; Ahmad, S. Effect of Elevated Temperatures on Mechanical Performance of Normal and Lightweight Concretes Reinforced with Carbon Nanotubes. Fire Technol. 2018, 54, 1331-1367. [CrossRef]

21. Maraveas, C.; Wang, Y.; Swailes, T. Thermal and mechanical properties of 19th century fireproof flooring systems at elevated temperatures. Constr. Build. Mater. 2013, 48, 248-264. [CrossRef]

22. Maraveas, C.; Wang, Y.; Swailes, T. Fire resistance of 19th century fireproof flooring systems: A sensitivity analysis. Constr. Build. Mater. 2014, 55, 69-81. [CrossRef]

23. Chen, M.; Hou, X.; Zheng, W.; Wu, B. Review and analysis of researches on the critical temperature of concrete high-temperature burst and fiber content. J. Build. Struct. 2017, 1, 161-170.

24. Libre, N.A.; Shekarchizadeh, M.; Mahoutian, M.; Soroushian, P. Mechanical properties of hybrid fiber reinforced lightweight aggregate concrete made with natural pumice. Constr. Build. Mater. 2011, 25, 2458-2464. [CrossRef]

25. Liu, X.; Wu, T.; Liu, Y. Stress-strain relationship for plain and fibre-reinforced lightweight aggregate concrete. Constr. Build. Mater. 2019, 225, 256-272. [CrossRef]

26. Afroughsabet, V.; Ozbakkaloglu, T. Mechanical and durability properties of high-strength concrete containing steel and polypropylene fibers. Constr. Build. Mater. 2015, 94, 73-82. [CrossRef]

27. Li, J.J.; Niu, J.G.; Wan, C.J.; Jin, B.; Yin, Y.L. Investigation on mechanical properties and microstructure of high performance polypropylene fiber reinforced lightweight aggregate concrete. Constr. Build. Mater. 2016, 118, 27-35. [CrossRef]

28. Liu, Q.; Xiao, J.; Pan, Z.; Li, L. Modeling Research on Waste Concrete Aggregate and Waste Brick Aggregate Recycled Concrete. J. Build. Struct. 2020, 41, 133-140.

29. Fu, F.; Parke, G.A.R. Assessment of the Progressive Collapse Resistance of Double-Layer Grid Space Structures Using Implicit and Explicit Methods. Int. J. Steel Struct. 2018, 18, 831-842. [CrossRef]

30. Fu, F.; Lam, D.; Ye, J. Moment resistance and rotation capacity of semi-rigid composite connections with precast hollowcore slabs. J. Constr. Steel Res. 2010, 66, 452-461. [CrossRef]

31. Wang, L.; Shen, N.; Zhang, M.; Fu, F.; Qian, K. Bond performance of Steel-CFRP bar reinforced coral concrete beams. Constr. Build. Mater. 2020, 245, 118456. [CrossRef]

32. Chen, X.; Wan, D.-W.; Jin, L.-Z.; Qian, K.; Fu, F. Experimental studies and microstructure analysis for ultra high-performance reactive powder concrete. Constr. Build. Mater. 2019, 229, 116924. [CrossRef]

33. Xu, M.; Gao, S.; Guo, L.; Fu, F.; Zhang, S. Study on collapse mechanism of steel frame with CFST-columns under column-removal scenario. J. Constr. Steel Res. 2018, 141, 275-286. [CrossRef]

34. Fu, F. Advanced Modeling Techniques in Structural Design; John Wiley \& Sons: Hoboken, NJ, USA, 2015; ISBN 978-1-118-82543-3.

35. Fu, F. Fire Safety Design for Tall Buildings; Taylor Francis: Abingdon, UK, 2021; ISBN 978-0-367-44452-5.

36. Han, B.; Xiang, T.-Y. Axial compressive stress-strain relation and Poisson effect of structural lightweight aggregate concrete. Constr. Build. Mater. 2017, 146, 338-343. [CrossRef] 